\title{
Fault Location for Resonant Grounded System Based on Zero-Sequence Current Increment Method
}

\author{
Lv Jin, Ju Rong, Wu Mingyu, Liu Jiajia, and He Xiongfeng
}

\begin{abstract}
In order to deal with the problem of single-phase earthing fault in resonant grounded system, a new method of fault line and segment selection was proposed using zero-sequence current increment through analyzing the line fault on substation outlet and the change of the fault component of zero-sequence current. The zero-sequence current in the line will change when the inductance of arc-suppression coil is changed. The method determines the fault location based on the characteristic of the change in the line. The effects of resistance grounding can be eliminated by converting zero-sequence currents to the same voltage. Matlab simulation experiments verify the correctness and validity of the method.
\end{abstract}

Index Terms-Resonant grounded system, single-phase earthing fault, zero-sequence current increment method, fault location, arc-suppression coil.

\section{INTRODUCTION}

In China, most distribution networks employ small current grounded system and more neutral point resonant grounded systems [1] have been put into use. Single-phase earthing fault accounts for $70 \%$ of total fault in distribution system [2]. When single-phase earthing fault occurs in resonant grounded system, the grounded current is very small and the line to line voltages are almost unchanged, which has little impact on power load. However, fault phase voltage drops almost to zero and non-fault phase voltage increases to $\sqrt{3}$ times compared with the original voltage [3]. If the distribution network continues to run for a long time, single-phase earthing fault may change into double-phase earthing fault [4]. Therefore, fault line and segment selection must be carried out as soon as possible after the single-phase earthing fault occurs in order to reduce outage time and improve the reliability of power supply.

Fault location of distribution network includes off-line fault location and on-line fault location. One is called off-line fault location, which is carried out by some methods after the fault line power is cut off. There are many off-line fault location methods such as traveling wave methods [5]-[6] and synthetic method of AC-DC [7]-[8]. A method based on traveling wave is proposed by some papers, whose disadvantage is that there are many muti-stage branch lines in the distribution system, so the

Manuscript received October 16, 2012; revised November 23, 2012. This work was supported in part by Nanjing Normal University.

Lv Jin is with the electrical power system and automation, Nanjing Normal University. (e-mail:lvjinjs2008@163.com). reflected traveling wave is so complicated after single phase earthing fault occurs and it is difficult to distinguish the characteristic wave of the fault point accurately. The other is on-line fault location when the fault line still works.

"S" signal injecting method as [9]-[10] presents can't determine fault point effectively, because injected signal can flow in healthy section when signal phase earthing fault via high resistance occurs.

Nowadays there are many methods of fault line and segment for single-phase earthing fault in ungrounded system, but few ones for resonant grounded system [11]-[12]. The zero-sequence current increment method is proposed through analyzing the characteristic of the fault component of zero-sequence current for single-phase earthing fault in resonant grounded system. Fault line and segment can be selected by this method.

\section{FAult Location OF Zero-SEQuence CuRRENT INCREMENT METHOD}

\section{A. Faut Line Selection Theory}

The zero-sequence equivalent circuit is shown in the Fig. 1 , which is used to analyze the zero-sequence current and voltage after single-phase earthing short circuit occurs in resonant grounded system. It includes $\mathrm{n}$ lines and the fault occurs in the line $\mathrm{n} . \mathrm{C} 1 \sim \mathrm{Cn}$ is shown as earth capacitance of $\mathrm{n}$ lines respectively. When arc-suppression coil is not yet adjusted, assume the zero-sequence current of each line as $\dot{I}_{11}, \dot{I}_{21} \ldots \dot{I}_{n-1,1}, \dot{I}_{n 1}$, the zero-sequence voltage as $\dot{U}_{o 1}$, and inductance value as $L_{1}$; After adjusting arc-suppression coil, the zero-sequence current as $\dot{I}_{12}, \dot{I}_{22} \ldots \dot{I}_{n-1,2}, \dot{I}_{n 2}$, the zero-sequence voltage as $\dot{U}_{02}$, and inductance value as $L_{2}$.

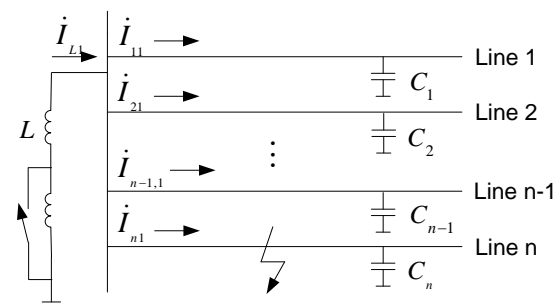

Fig. 1. Zero sequence net work of fault line selection

Before the reactance value of arc-suppression coil changes, the zero-sequence current of healthy lines:

$$
\dot{I}_{i 1}=j w C_{i} \dot{U}_{0}, \quad i=1,2, . n-
$$


The zero-sequence current of fault line:

$$
\dot{I}_{n 1}=\dot{I}_{L 1}-\sum_{i=1}^{n-1} \dot{I}_{i 1}
$$

After the reactance value of arc-suppression coil changes, the zero-sequence current of healthy lines:

$$
\dot{I}_{i 2}=j w C_{i} \dot{U}_{02}, \quad i=1,2, . n-
$$

The zero-sequence current of fault lines:

$$
\dot{I}_{n 2}=\dot{I}_{L 2}-\sum_{i=1}^{n-1} \dot{I}_{i 2}
$$

When single-phase earthing fault occurs in the zero-sequence network of Fig.1, because $\dot{U}_{o 1}$ is approximately equal to $\dot{U}_{02}$, the increment of zero -sequence current can be calculated as follow:

$$
\begin{aligned}
& \Delta \dot{I}_{i}=\dot{I}_{i 2}-\dot{I}_{i 1}=0, \quad i=1,2, . n- \\
& \Delta \dot{I}_{n}=\dot{I}_{n 2}-\dot{I}_{n 1}=\dot{I}_{L 2}-\sum_{i=1}^{n-1} \dot{I}_{i 2}-\left(\dot{I}_{L 1}-\sum_{i=1}^{n-1} \dot{I}_{i 1}\right)= \\
& \dot{I}_{L 2}-\dot{I}_{L 1}=\dot{U}_{01} / 3 j w L_{2}-\dot{U}_{01} / 3 j w L_{1}
\end{aligned}
$$

As is known from formula (5) and (6), zero-sequence current on the healthy lines has no change, but the increment of zero-sequence current on fault line is equal to the variation of compensated current. So the characteristic differences can be utilized to select fault line in resonant grounded system.

\section{B. Fault Segment Selection Theory}

The circuit of fault segment selection is shown in the Fig. 2 and point $f$ occurs a single-phase earthing fault. The zero-sequence current in front of point $f$ and behind it is analyzed before and after the reactance value of arc-suppression coil changes.

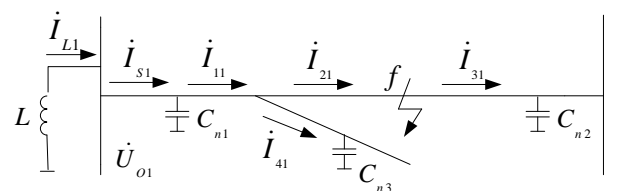

Fig. 2. Zero sequence network of fault segment selection

Part A indicates that the variation of $\dot{I}_{s 1}$ is consistent with that of $\dot{I}_{L 1}$. Before the reactance value changes, the zero-sequence current in front of point $f$ and behind it is as follow:

$$
\begin{gathered}
\dot{I}_{21}=\dot{I}_{S 1}-j w C_{n 1} \dot{U}_{01}-j w C_{n 3} \dot{U}_{01} \\
\dot{I}_{31}=j w C_{n 2} \dot{U}_{01}
\end{gathered}
$$

After the reactance value changes, that is as follow:

$$
\begin{gathered}
\dot{I}_{22}=\dot{I}_{S 2}-j w C_{n 1} \dot{U}_{02}-j w C_{n 3} \dot{U}_{02} \\
\dot{I}_{32}=j w C_{n}{ }_{2}
\end{gathered}
$$

As is known from part $\mathrm{A}, \dot{U}_{o 1}$ is approximately equal to $\dot{U}_{O_{2}}$, the zero-sequence current increment in front of point $f$ can be calculated as follow:

$$
\begin{aligned}
& \Delta \dot{I}_{2}=\dot{I}_{22}-\dot{I}_{21}=\dot{I}_{s 2}-j w \dot{U}_{02}\left(C_{n 1}+C_{n 3}\right)- \\
& {\left[\dot{I}_{s 1}-j w \dot{U}_{01}\left(C_{n 1}+C_{n 3}\right)\right]=\dot{I}_{s 2}-\dot{I}_{s 1}}
\end{aligned}
$$

Because $\dot{I}_{S 1}$ and $\dot{I}_{L 1}$ are on the fault path, we can get the following equation:

$$
\begin{aligned}
& \dot{I}_{2}=\dot{I}_{S 2}-\dot{I}_{S 1}=\dot{I}_{L 2}-\dot{I}_{L 1}= \\
& \dot{U}_{01} / 3 j w L_{2}-\dot{U}_{01} / 3 j w L_{1}
\end{aligned}
$$

The zero-sequence current increment behind point $f$ is as follow:

$$
\Delta \dot{I}_{3}=\dot{I}_{32}-\dot{I}_{31}=0
$$

As is known from formula (12) and (13), zero-sequence current increment in front of fault point has no change, while that behind fault point is equal to the variation of compensated current. Therefore, the differences can be employed to select fault segment.

\section{IMPROVED ZERO-SEQUENCE CURRENT INCREMENT METHOD}

\section{A. Theory of Improved Zero-sequence Current Increment Method}

Assume that single-phase earthing fault occurs via resistance in the circuit of Fig.1. As is known from empirical formula $\dot{U}_{0}=-\dot{E}_{a} /[1+j R(3 w c-1 / w L)]$, adjusting reactance value of arc-suppression coil changes $\dot{U}_{o}$. The variation of the zero-sequence voltage makes the zero-sequence current in healthy lines and non-fault path of fault line change. The method of section II can't be directly utilized and it should be improved

If we convert all the zero-sequence current into the same voltage such as $\dot{U}_{o 1}$, the influence of the variation of $\dot{U}_{o}$ can be effectively eliminated. Supposing that single-phase earthing fault occurs via resistance in line $n$ of Fig.1, the zero-sequence current of healthy lines and fault line have been expressed in formula (1)-(4).

Convert $\dot{I}_{i 2}$ of formula (3) as:

$$
\dot{I}_{i 2}^{\prime}=\dot{I}_{i 2} \frac{\dot{U}_{01}}{\dot{U}_{02}}=j w C_{i} \dot{U}_{02} \frac{\dot{U}_{01}}{\dot{U}_{02}}=j w C_{i} \dot{U}_{01}
$$

Convert $\dot{I}_{i 1}$ of formula (1) as: 


$$
\dot{I}_{i 1}^{\prime}=\dot{I}_{i 1}=j w C_{i} \dot{U}_{01}
$$

The converted zero-sequence current increment is as follow:

$$
\Delta \dot{I}_{i}^{\prime}=\dot{I}_{i 2}^{\prime}-\dot{I}_{i 1}^{\prime}=0
$$

Similarly,

$$
\begin{aligned}
& \Delta \dot{I}_{n}^{\prime}=\dot{I}_{n 2}^{\prime}-\dot{I}_{n 1}^{\prime}=\dot{I}_{n 2} \dot{U}_{01} / \dot{U}_{02}-\dot{I}_{n 1}= \\
& \left(\dot{I}_{L 2}-\sum_{i=1}^{n-1} \dot{I}_{i 2}\right) \dot{U}_{01} / \dot{U}_{02}-\left(\dot{I}_{L 1}-\sum_{i=1}^{n-1} \dot{I}_{i 1}\right)= \\
& \dot{I}_{L 2} \dot{U}_{01} \dot{U}_{02}-\dot{I}_{L 1}=\dot{U}_{01} / 3 j w L_{2}-\dot{U}_{01} / 3 j w L_{1}
\end{aligned}
$$

From the formula (16) and (17), the method for part A of section II still can be employed to select fault line after the zero-sequence current has been converted.

Supposing that single-phase earthing fault occurs via resistance in the system of Fig. 2, we can still use the theory of part B of section II to select fault segment after the zero-sequence current has been converted.

\section{B. Simplified Line and Segment Selection Criterion}

From the fault characteristics, the zero-sequence voltage modulus value network-wide is almost equal before the reactance value of arc-suppression coil changes. That is the same after the reactance value changes. The corresponding phase angle error is very small after the zero-sequence current is converted into the same voltage. So the formula
(17) can be simplified as follow:

$$
\left|\Delta \dot{I}_{n}^{\prime}\right|=I_{n 2}^{\prime}-I_{n 1}^{\prime}=I_{n 2} U_{01} / U_{02}-I_{n 1}
$$

$I_{n 2}^{\prime}, I_{n 1}^{\prime}, I_{n 2}, I_{n 1}$ is shown as the amplitude of the zero-sequence current, and $U_{01}, U_{02}$ shown as that of the zero-sequence voltage.

The formula (5), (6), (12), (13), and (16) can be similarly simplified. We only need to measure the zero-sequence current and voltage modulus value of each line in order to make use of the method to determine fault point.

\section{SimUlating EXPERIMENT OF MATLAB}

$10 \mathrm{Kv}$ simulation model with a neutral point of arc-suppression coil grounding is built by simulation of Matlab. Simulation model is shown in Fig.3, it includes two transmission lines, which are "Three-phase PI Section Line" models. The length of line 1 line 2 is $10 \mathrm{~km} \cdot 22 \mathrm{~km}$ respectively. The "Three-phase V-I measurement" is at the beginning of each line, which can transform measurement current and voltage signal into simulink signal

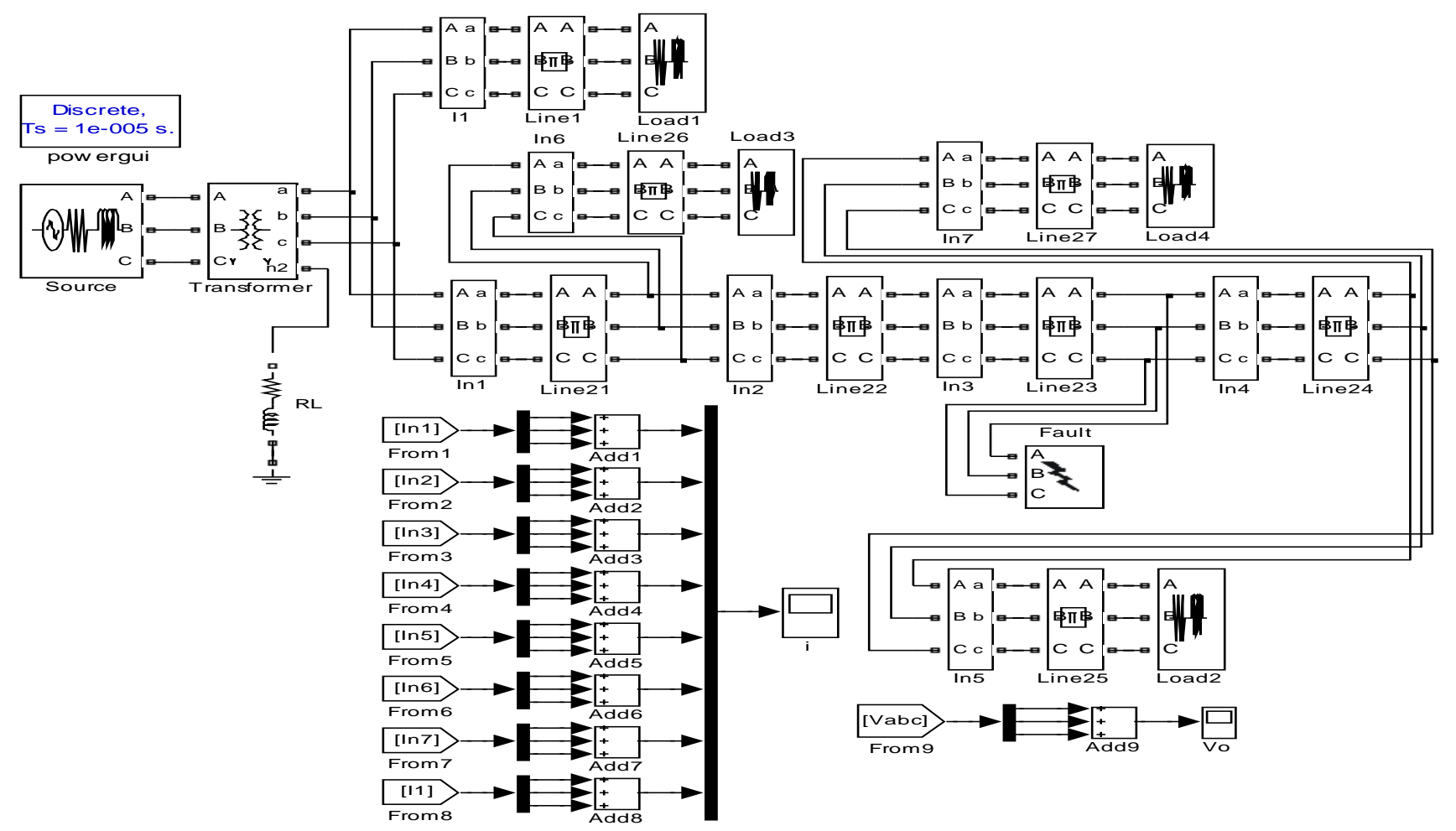

Fig. 3. Simulation model of $10 \mathrm{kv}$ distribution network

The simplified simulation model Fig. 3 is shown in Fig4. The length of branch BB1, AA1, A1A3, A3A4, A1A5,
A3A6 is $10 \mathrm{~km}, 4 \mathrm{~km}, 7 \mathrm{~km}, 5 \mathrm{~km}, 4 \mathrm{~km}, 2 \mathrm{~km}$. Single-phase earthing fault occurs via a $1.5 \mathrm{~K} \Omega$ resistance in the 
middle of branch A1A2.

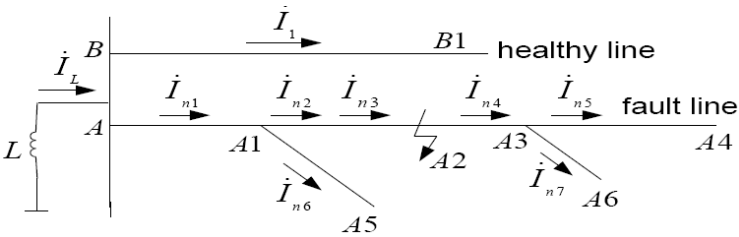

Fig. 4. Simplified line of simulation model

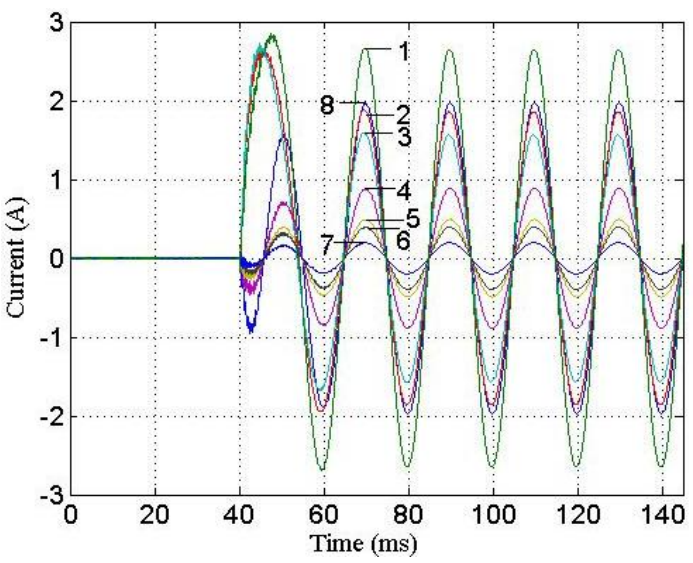

Fig. 5. Zero sequence current waveforms before the inductance of arc-suppression coil changes

$1-$ zero sequence current $\dot{I}_{n 1} ; 2-\dot{I}_{n 2} ; 3-\dot{I}_{n 3} ; 4-\dot{I}_{n 4}$;

$5-\dot{I}_{n 5} ; 6-\dot{I}_{n 6} ; 7-\dot{I}_{n 7} ; 8-\dot{I}_{1}$.

Zero-sequence current waveforms before and after the reactance value of arc-suppression coil changes are shown in Fig.5 and Fig.6.

The modulus values of zero-sequence current before and after the reactance value of arc-suppression coil changes are shown in Table I. At the same time, the converted currents are also seen as Table I.

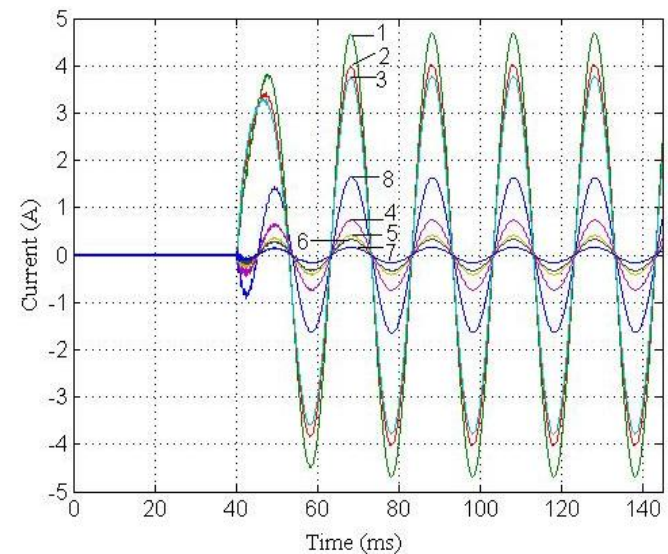

Fig. 6. Zero sequence current waveforms after the inductance of arc-suppression coil changes

$$
\begin{aligned}
& \text { 1- zero sequence current } \dot{I}_{n 1} ; 2-\dot{I}_{n 2} ; 3-\dot{I}_{n 3} ; 4-\dot{I}_{n 4} ; \\
& 5-\dot{I}_{n 5} ; 6-\dot{I}_{n 6} ; 7-\dot{I}_{n 7} ; 8-\dot{I}_{1} .
\end{aligned}
$$

Shown in the Table I, firstly we analyze line BB1 and AA4, the zero-sequence current increment for branch AA1 of line AA4 is $2.978 \mathrm{~A}$ while that of line BB1 is nearly zero $(0.24 \mathrm{~mA})$, so the fault point is in line AA1 or behind it.Then, line A1A5 and A1A3 are analyzed. Judging from the same reason, fault point is in line $\mathrm{A} 1 \mathrm{~A} 3$ or behind it. The zero-sequence current in front of point $\mathrm{A} 2$ varies largely(3.011 A), but that behind point A2 doesn't vary. Therefore, point A2 can be regarded as fault point.

\begin{tabular}{|c|c|c|c|c|c|c|c|c|c|}
\hline \multirow{2}{*}{\multicolumn{2}{|c|}{ Current variation }} & \multicolumn{8}{|c|}{ Zero-sequence current modulus values } \\
\hline & & $\mathrm{I}_{\mathrm{n} 1}$ & $\mathrm{I}_{\mathrm{n} 2}$ & $\mathrm{I}_{\mathrm{n} 3}$ & $\mathrm{I}_{\mathrm{n} 4}$ & $\mathrm{I}_{\mathrm{n} 5}$ & $\mathrm{I}_{\mathrm{n} 6}$ & $\mathrm{I}_{\mathrm{n} 7}$ & $\mathrm{I}_{1}$ \\
\hline \multirow{2}{*}{$\begin{array}{c}\text { Before } \\
\text { converting }\end{array}$} & $\begin{array}{l}\text { before } \mathrm{L} \\
\text { changes }\end{array}$ & 2.651 & 1.860 & 1.562 & 0.881 & 0.490 & 0.391 & 0.191 & 1.962 \\
\hline & $\begin{array}{c}\text { after L } \\
\text { changes }\end{array}$ & 4.652 & 4.031 & 3.780 & 0.741 & 0.412 & 0.331 & 0.160 & 1.642 \\
\hline \multirow{2}{*}{$\begin{array}{c}\text { After } \\
\text { converting }\end{array}$} & $\begin{array}{l}\text { before } \mathrm{L} \\
\text { changes }\end{array}$ & 2.651 & 1.860 & 1.562 & 0.881 & 0.490 & 0.391 & 0.191 & 1.962 \\
\hline & $\begin{array}{c}\text { after } L \\
\text { changes }\end{array}$ & 5.629 & 4.877 & 4.573 & 0.897 & 0.498 & 0.401 & 0.193 & 1.986 \\
\hline
\end{tabular}

TABLE I: Zero SEQUENCE CURRENT-AmPLitude VALUES AT EACH SAMPLING Point

\section{CONCLUSION}

This paper puts forward the zero-sequence current increment method based on analyzing the single-phase earthing fault characteristics in resonant grounded system. We can make use of the method to select fault line and segment. This method is not only accurate and reliable, but also saves equipment costs, reduces application difficulty, which looks forward to be applied to the construction of smart distribution network.

\section{REFERENCES}

[1] X.-J. Chen, L. Wang, and J.-S. Sui, "A new method of single-phase earthing fault location for distribution network," Electric Power, 2011, vol. 44, no. 10, pp. 33-36.
[2] J.-Z. Sun, J.-G. Yan, and X.-Y. Quan, "Development and application of positioning device for earthing line selection," Rural Electrification, 2004, vol. 3, pp. 41-42, 2002.

[3] Z. Qi and Y.-H. Yang, "Analysis of the methods of single-phase earthing line selection in neutral ineffectively grounded systems," Automation of Electric Power Systems, 2004, vol. 28, vol. 14, pp. $1-4$.

[4] L.-Y. Wang, Single-phase earthing fault line selection based small current grounded system of Agent, Shanghai: Tongji University, 2008.

[5] F. Yan, Q.-X. Yang, Z. Qi et al., "Study on fault location scheme for distribution network based on traveling wave theory," in Proc. of the CSEE, 2004, vol. 24, no. 9, pp. 37-43.

[6] S.-N. Yu, H. Bao, Y.-H. Yang, "Practicalization of fault location in distribution lines," in Proc. of the CSEE, 2008,vol. 28, no. 28, pp. 86-90.

[7] D.-M. Si, Z. Qi, M. Qian et al., "Study and realization on fault location about $10 \mathrm{kV}$ distribution network," Power System Protection and Control, 2008, vol. 36, no. 18, pp. 24-28. 
[8] L. Zhang, Y.-H. Yang, and X.-Y. Yang, "Research and implementation of off-line fault location for distribution network," Automation of Electric Power Systems, 2009, vol. 33, no. 1, pp. 70-74.

[9] J. Ma, W.-H. Yu, W.-Y. Che et al., "A novel fault localizer of tree form distribution networks based on improved $\mathrm{S}$ injecHe Jianqiang.Research of fault location for distribution network based on S injection method," Journal of Electric Power, 2011, vol. 26, no. 2, pp. 124-126.

[10] Z. Qi, Z. Zhen, and Y.-H. Yang, "Research on method of single-phase. earthing fault section location in neutral point resonant grounded system," Automation of Electric Power Systems, 2010, vol. 34, no. 9, pp. 77-80.

[11] H.-C. Shu, J. Liu, and C. Wang, "Adaptive method for fault circuit selection in arc suppression coils system by using transient energy," Automation of Electric Power Systems, 2006, vol. 30, no. 11, pp. $72-76$.

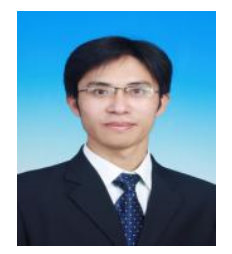

Lv Jin was born in 1987. He received his B.S. Degree from Nanjing Normal University, China, and currently studies in Nanjing Normal University for his M.S. His research field is fault location of distribution network. Ju Rong was born in 1964, received his M.S. Degree from Southeast University, China, and currently is a professor, mast supervisor of Nanjing Normal University. His main research fields are distribution automation system and artificial intelligence and expert systems.

Mingyu Wu was born in 1989. He received his B.S. Degree from Nanjing Normal University, and currently studies in Nanjing Normal University for his M.S. His research field is electrical power system and automation.

Jiajia Liu was born in 1988. She currently studies in Nanjing Normal University for her M.S. Her research field is fault location of power transmission .network.

Feng Xiong was born in 1985. He currently studies in Nanjing Normal University for his M.S. His research field is wind power generation. 